Available online at GSC Online Press Directory

GSC Biological and Pharmaceutical Sciences

e-ISSN: 2581-3250, CODEN (USA): GBPSC2

Journal homepage: https://www.gsconlinepress.com/journals/gscbps

(RESEARCH ARTICLE)

\title{
Propagation of Carissa edulis using stem cuttings for domestication and conservation in Uganda
}

\author{
Grace Abigaba 1,*, Denis Byabashaija Mujuni ${ }^{2}$, Emilly Kamusiime ${ }^{2}$, Dan Kazigaba ${ }^{3}$ and Richard Oluk ${ }^{1}$ \\ 1 Tree improvement and Germplasm Research Program, National Forestry Resources Research Institute, Uganda. \\ ${ }^{2}$ Forest Conservation and Management Research Program, National Forestry Resources Research Institute, Uganda. \\ ${ }^{3}$ Forest Products and Services Research Program, National Forestry Resources Research Institute, Uganda.
}

Publication history: Received on 17 July 2020; revised on 06 September 2020; accepted on 09 September 2020

Article DOI: https://doi.org/10.30574/gscbps.2020.12.3.0230

\begin{abstract}
Carissa edulis is a plant of $5 \mathrm{~m}$ high at maturity. It grows in the Savannah woodlands of Uganda and is commonly found on ant-hills. Carissa edulis is used as a remedy for treatment of headache, chest complains, rheumatism, oedema, gonorrhea, syphilis, sickle cell anaemia, cough, ulcer, tooth-ache, and worms. Poor harvesting methods of Carissa edulis for medicine such as uprooting the whole plant threatens its existence. Its seeds are scarce because ants, birds and animals eat them hence propagation by seed is a challenge. Carissa edulis has not been in cultivation therefore its most suitable propagation method is unknown. These create the need to explore the most appropriate propagation method for Carissa edulis as a means of capturing its germplasm from the wild for purposes of its domestication, conservation and continuous availability to the communities. An experiment was conducted at the National Forestry Resources Research Institute, Uganda with an objective of investigating the best method of propagating Carissa edulis using stem cuttings. The cuttings were categorized into softwood, semi-hardwood and hardwood cuttings and 50 of each treated with Indole-butyric acid (IBA) in concentrations of $0.6 \mathrm{w} / \mathrm{w}$ and $0.8 \mathrm{w} / \mathrm{w}$ plus a control and replicated 3 times.The rooting media used included: sterilized sand and soil and milled Pine bark (soaked in water for a night). Results showed the best method for propagation of Carissa edulis is by use of softwood stem cuttings treated with IBA rooting hormone of $0.8 \mathrm{w} / \mathrm{w}$ and placed in sterilized Sand as propagation medium.
\end{abstract}

Keywords: Carissa edulis; Stem cutting; Propagation; Rooting hormone

\section{Introduction}

Medicinal plants are a primary or supplementary element of $80 \%$ of the world's health care practices. Worldwide use of medicinal plants has risen significantly over the past two decades, fueling development of an important agricultural market valued at over US \$ 60 billion annually [1]. This rapid rise in demand, however, has not been matched by equal increases in cultivation [2]. Also, the pharmaceutical industry is largely dependent upon the wild populations for supply of these plant species for the extraction of their intrinsic bioactive component [3]. Because the land sources of wild medicinal plants are limited, attempts to allow the replenishment or cultivation of this important flora is more necessary and there is an urgent need to develop effective propagation methods for cultivation of these important medicinal plants which will ultimately lead to their conservation as well as supply for commercial use [4]. Therefore, vegetative propagation technologies are an integral component in Carissa improvement and conservation programs, in order to complement seed banking and ex situ measures for long-term conservation and clonal propagation.

\footnotetext{
* Corresponding author: Grace Abigaba

National Forestry Resources Research Institute, Box 1752, Kampala, Uganda.
} 
Carissa edulis is a savannah woodland tree species commonly found on ant-hills in Uganda which grows up to $5 \mathrm{~m}$ high at maturity. It is used as a remedy for treatment of headache, chest complains, rheumatism, oedema, gonorrhoea, syphilis, rabies and it is also used as a remedy for fever, sickle cell anaemia, cough, ulcer, tooth-ache, and worm infestation [5]. Traditional healers use roots concoctions as pain killer and malaria treatment. Carrisa products enhances indigestion, treats dysentery, chest and releases abnormal pains in pregnant mothers. Roots of Carissa edulis contain carissin that can be used to treat cancer, it has been successful in treating Herpes simplex virus [6]. Orwa [7] states that roots of Carissa edulis contain an active ingredient, carissin that may prove useful in the treatment of cancer. The twigs contain quebrachytol and cardioglycosides that are useful as an anthelmintic against tapeworm.

In Guinea, the boiled leaves are applied as poultice to relieve toothache. Root bark is mixed with spices and used as an enema for lumbago and other pains in Ghana; root scrapings are used for glandular inflammation; ground-up roots are used as a remedy for venereal diseases, to restore virility, to treat gastric ulcers, cause abortion, and as an expectorant. An infusion of roots along with other medicinal plants is used for treating chest pains, and a root decoction is also used for treating malaria.

However, many of these tree species are being threatened and are endangered because of poor harvesting method, conversion to agricultural lands, non-optimal management strategies, and overall deforestation rates that cannot keep up with natural regeneration of native forests. For example Carissa edulis when harvested for medicine the whole plant is uprooted which threatens its existence (field observation). Furthermore, the natural habitat for Carissa edulis which is mainly the forests are dwindling away at an alarming rate of $2.0 \%$ per annum leading to the loss of these tree species as noted by Nampewo [8]. This implies that these Carissa edulis tree species populations are getting less and soon may not be able to meet the needs of the community. This calls for its domestication and ex situ conservation.

Carissa edulis has naturally been growing in forests not on farm and therefore the most suitable propagation methods are not known. This creates the need to explore the most appropriate propagation methods for Carissa edulis. This is very crucial because the propagation methods will provide the means of capture Carissa edulis germplasm from the wild and increase its cultivation through domestication and conservation for continuous availability to the communities. It should be noted that seeds of Carissa are highly predated by birds and animals hence not easily available as a propagation material. This leads to exploring vegetative propagation methods including use of stem and root cuttings as propagation materials.

It is clear that some of medicinal plant species are not only hard to propagate sexually but also show complexities and undesirable characters out of sexual reproduction. There is an urgent need to develop effective propagation methods for cultivation of these important medicinal floras, which will ultimately lead to their conservation as well as their supply for commercial use [2]. Saffari et al., [9], found out that propagation by stem cuttings is quicker and cheaper than seed, if the cuttings are set in convenient media and right rooting hormone. In plant propagation, cuttings are dipped in a rooting hormone to stimulate root development. Anand et al. [10], performed growth performance study in Acorus calamus by treating with different concentrations of hormones and found significant results. Auxins are a class of plant growth substances often called phytohormones or plant hormones. Among the auxins $\alpha$-Naphthalene Acetic Acid (NAA) and Indole 3 Butyric Acid (IBA) are typically the principal auxins used for rooting and sprouting of cuttings and majority of plant species are responsive for rooting [11].

This study therefore, had the specific objective of developing appropriate vegetative propagation methods for Carissa edulis medicinal tree species using stem cuttings to produce plantlets for both on station, on farm domestication and conservation.

\subsection{Objectives}

To develop appropriate vegetative propagation methods for Carissa edulis medicinal tree species using stem cuttings to produce plantlets for both on station and on farm domestication and conservation.

\section{Material and methods}

A reconnaissance was carried out in Katugo Forest in Nakasongola district of Uganda to purposively identify Carissa edulis mature mother trees, with good characteristics like straightness, even branching, free from diseases and high growth vigor. Mother plants were identified and marked at minimum distance of $30 \mathrm{~m}$ intervals for stem cuttings and collection. The cuttings were categorized into softwood (not lignified), semi-hardwood (moderately lignified) and hardwood (highly lignified) cuttings depending on the branch part harvested. The cuttings were cut into $8 \mathrm{~cm}$ parts in length and put in cooler boxes to avoid desiccation and for ease of transportation to NaFORRI tree nursery. At NaFORRI 
tree nursery, the harvested cuttings were sprayed with Mancozeb 800 fungicide for disinfection after which the cuttings were further cut to $6 \mathrm{~cm}$ lengths, making sure that each cutting had at least 3 buds for good sprouting. These cuttings were treated with rooting hormone (IBA) with concentrations of $0.6 \mathrm{w} / \mathrm{w}$ and $0.8 \mathrm{w} / \mathrm{w}$ plus a control and treatments replicated 3 times.

In the nursery, soil (sterilized), sand (sterilized) and milled pine bark (overnight soaked in water) were used as the rooting media. These cuttings were placed in the propagator with two scars above the rooting media to form points for shooting and one scar into the rooting media to form the roots. A small bucket with water was placed in the middle of each tunnel for provision of moisture for cuttings growth (i.e the breather).

Mancozeb 800 fungicide was sprayed bi-weekly to avoid any fungal infections to the cuttings during the propagation period. The vegetative propagation studies were carried out in non-mist propagation tunnels constructed under a shade net of $10 \%$ heat intensive penetration. The tunnels were constructed using a white $0.5 \mathrm{~mm}$ polythene sheets, $4 \mathrm{~cm}$ wide wooden frames, connector aluminium wire and gravels. A randomized complete block with 3 factorial design was used with 3 replications with 3 types of cuttings $x 3$ concentrations of IBA rooting hormone $x 3$ types of rooting medium [12].

\subsubsection{Experimental treatments}

- 50 Softwood cuttings/ treated with $0.6 \mathrm{w} / \mathrm{w}$ IBA rooting hormone and placed in Sterilized Sand/Soil/milled Pine bark as rooting media respectively ;

- 50 Semi hardwood cuttings treated with $0.6 \mathrm{w} / \mathrm{w}$ IBA rooting hormone and placed in sterilized Sand/Soil/milled Pine bark as rooting media respectively;

- 50 Hardwood cuttings treated with 0.6 w/w IBA / Sand/soil/milled Pine bark;

- $\quad$ and same was done for $0.8 \mathrm{w} / \mathrm{w}$ IBA and the control (00 IBA)

Factorial design $=3$ types of stem cuttings $\mathrm{x} 3$ concentrations of IBA rooting hormone $\mathrm{x} 3$ types of rooting medium = 1350_experimental units.

\subsection{Data collection and analysis}

Data was collected weekly from each treatment, recording dates of placing the cuttings; Number of callused and rooted cuttings; Number of roots per cutting; and Length of the roots per each cutting. Number of shoots and leaves per cutting. Data were entered in Microsoft Excel spreadsheet and then imported into MINITAB version 12.22 and analyzed using analysis of variance (ANOVA) to obtain for number and length of roots and number of shoots and leaves.

\section{Results}

In Figure 1, also results showed that softwood stem cuttings treated with IBA $0.8 \mathrm{w} / \mathrm{w}$ and placed in sand as a rooting medium gave highest number (25) of rooted cuttings. This was followed by softwood cuttings treated with IBA $0.8 \mathrm{w} / \mathrm{w}$ placed in sand. The same trend followed for Semi hardwood cuttings. For hardwood cuttings there was no rooting.

Softwood cuttings treated with IBA $0.8 \mathrm{w} / \mathrm{w}$ and placed in sand showed the longest average of root length followed by softwood cuttings treated with IBA $0.6 \mathrm{w} / \mathrm{w}$ and placed in sand (Figure 2).

Results showed that there was leaf development in all treatments. This could be the presence of nutrients in the cuttings. It further showed that softwood cuttings treated with IBA $0.8 \mathrm{w} / \mathrm{w}$ and placed in sand gave the biggest average number of leaves (Figure 3).

Results showed that Softwood cuttings treated with IBA concentration of 0.8 and placed sand gave the highest biomass (Figure 4). For every category of cuttings, IBA concentration of 0.8 gave the highest biomass, same applies for sand as rooting medium. 


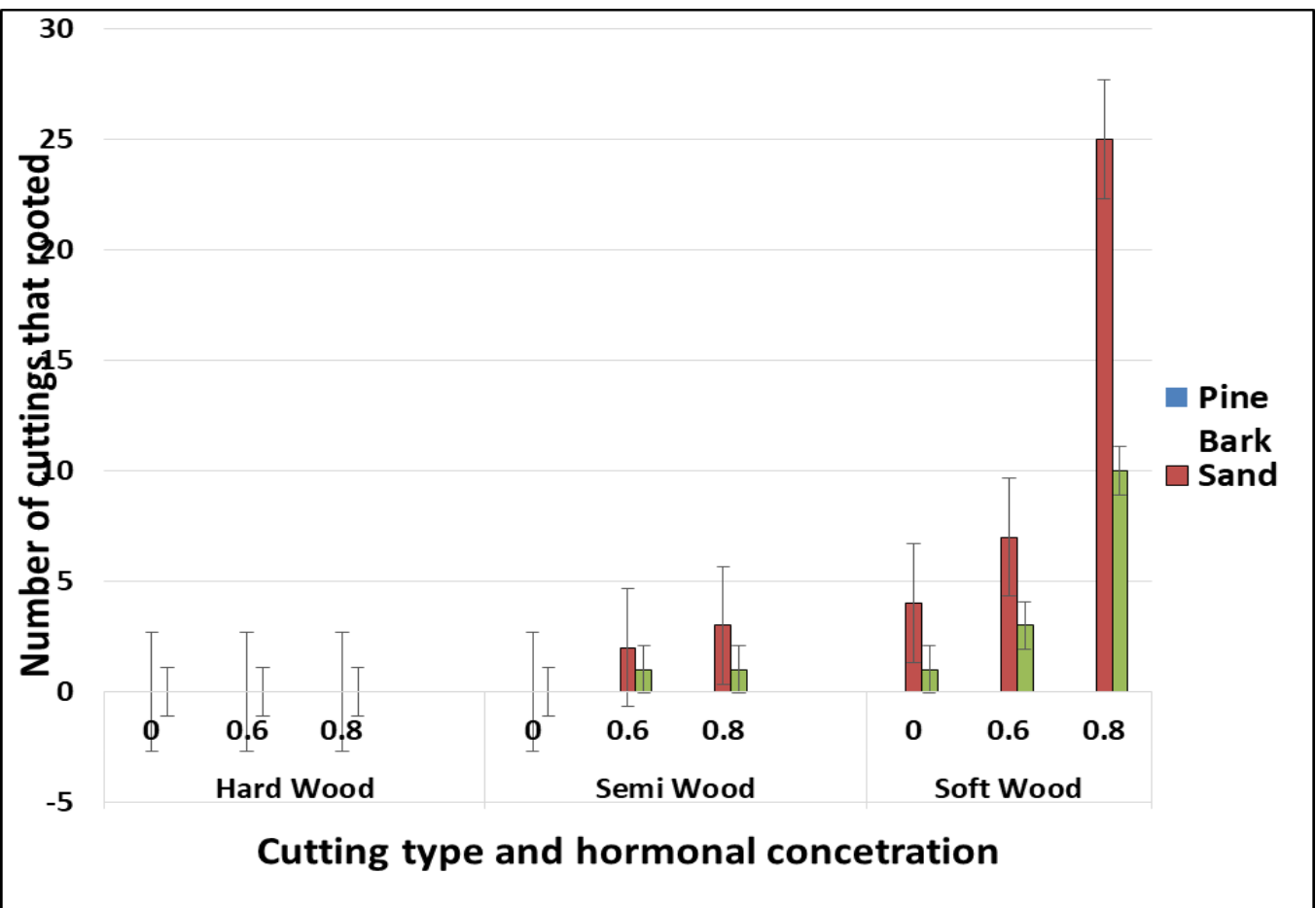

Figure 1 Rooting success of the different stem cuttings of Carissa edulis in the different rooting media and IBA concentration.

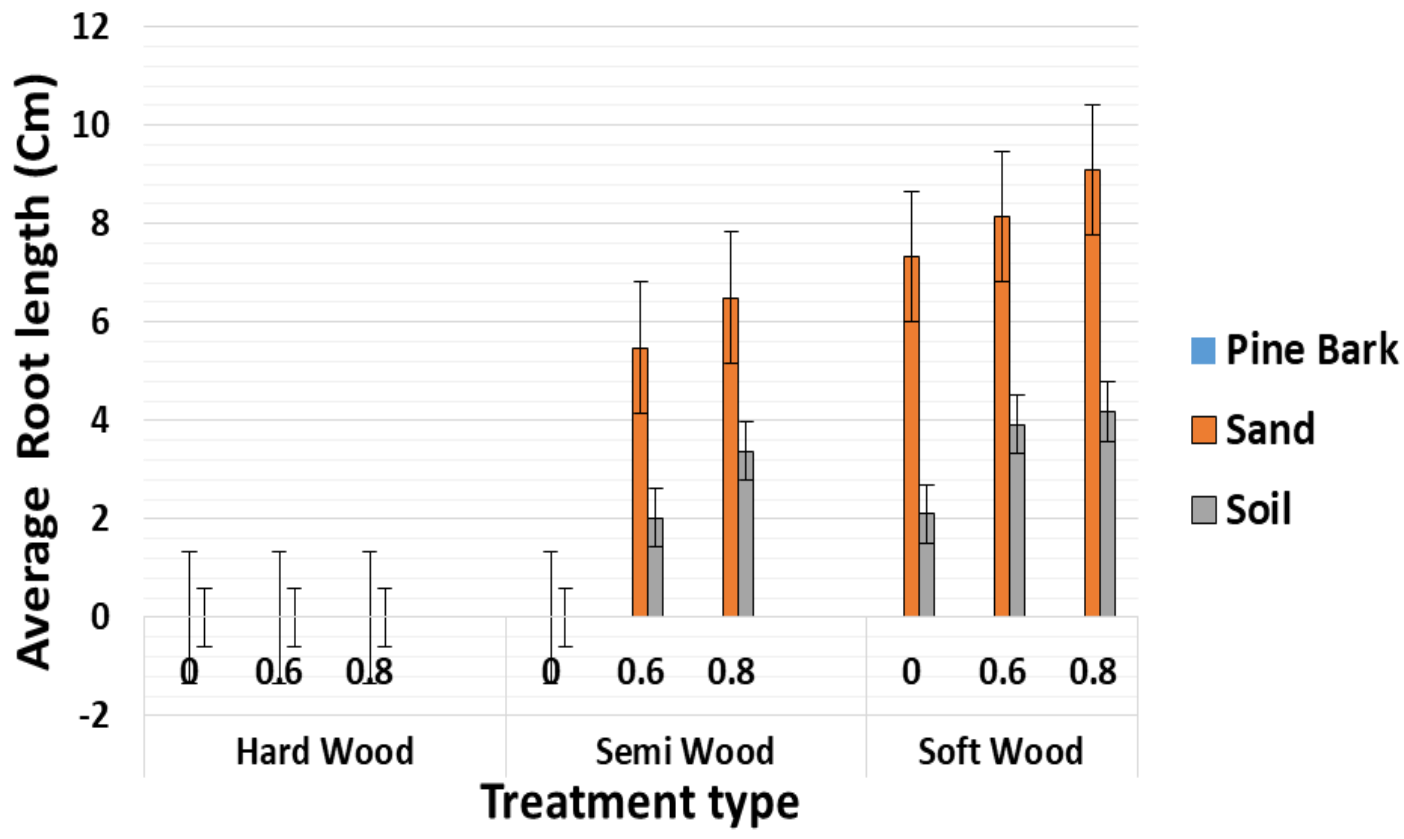

Figure 2 Root development of Carissa edulis stem cuttings in given different treatments 


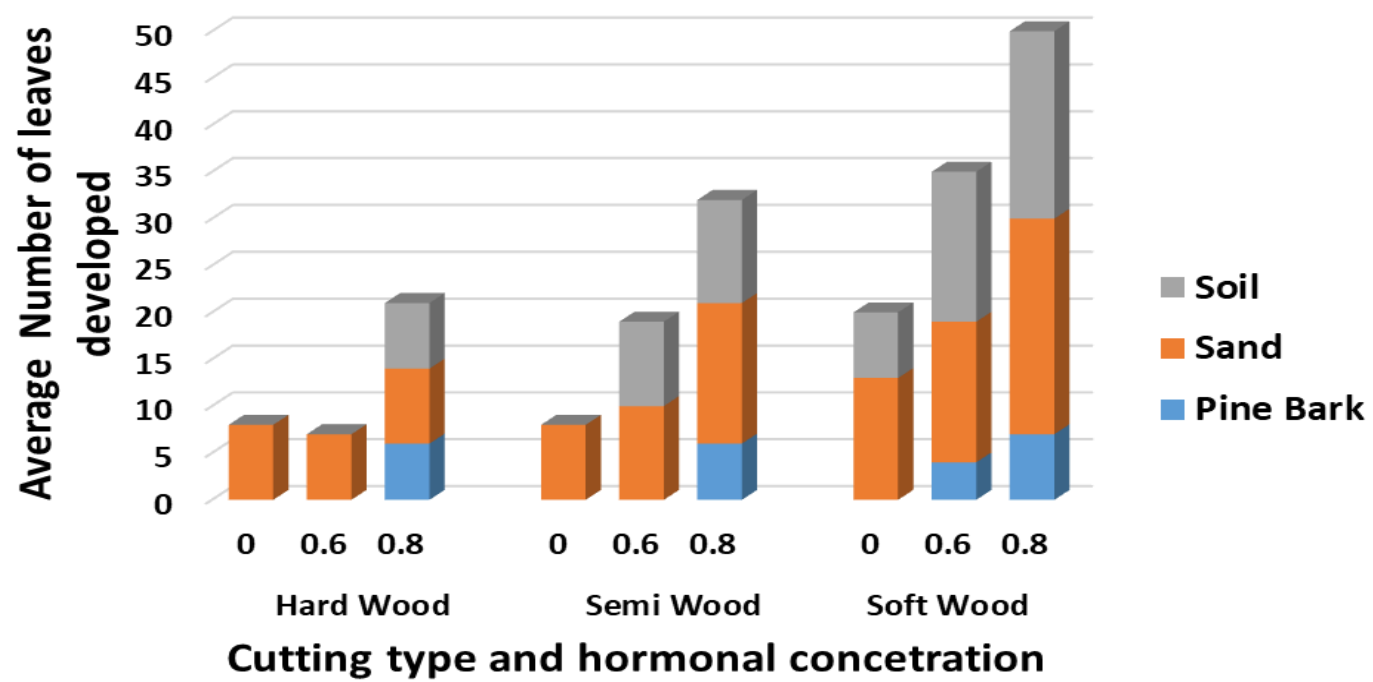

Figure 3 Biomass development of the different treatments (Leaves)

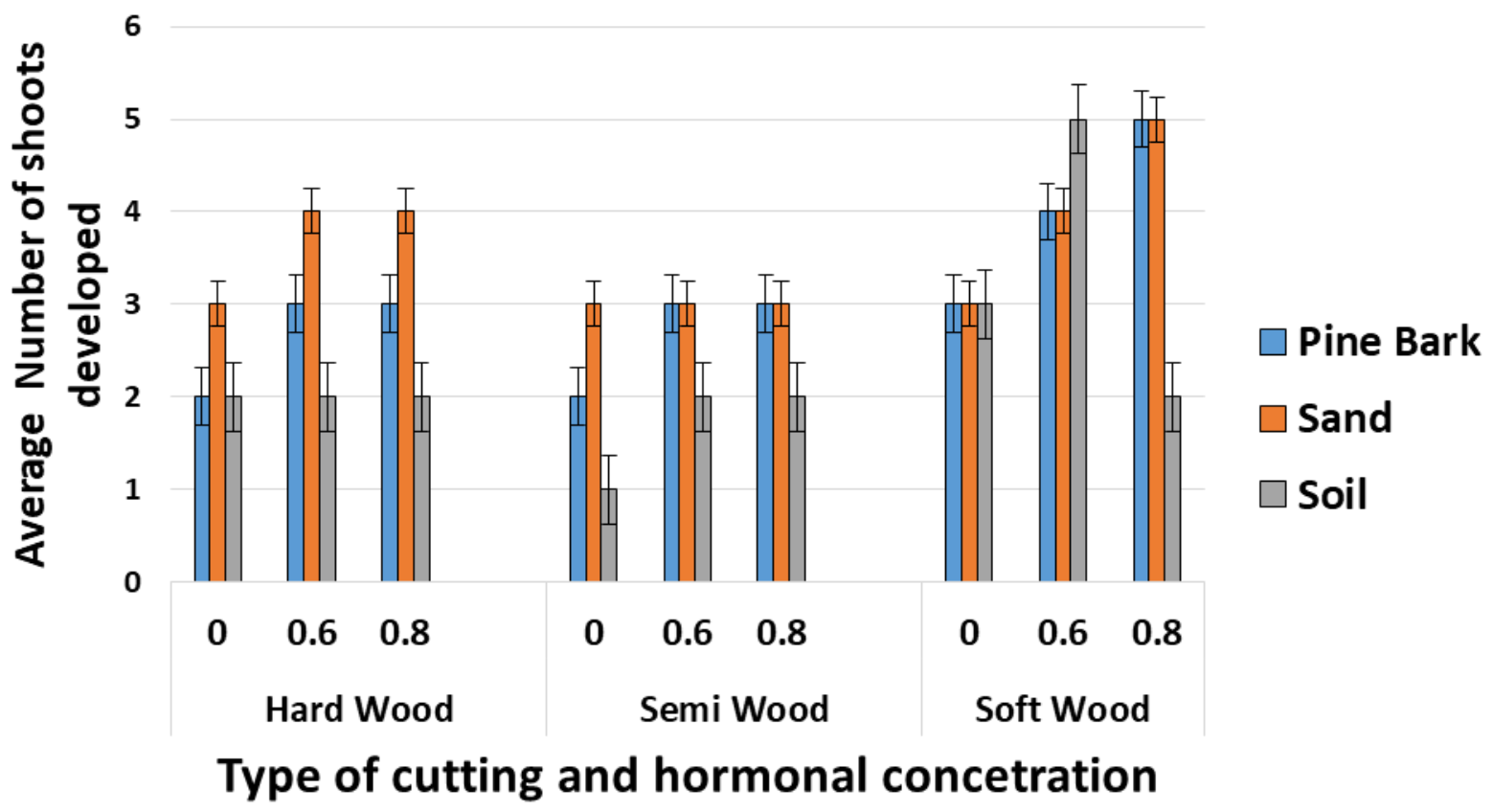

Figure 4 Biomass development of the different treatments (shoots)

\section{Discussions}

\subsection{Effect of different IBA rooting hormone concentration on root formation in stem cuttings of Carissa edulis}

The concentration levels of the artificial hormone being used to enhance root formation is very critical. This has been observed during the experiment where IBA with concentration of $0.8 \mathrm{w} / \mathrm{w}$ gave highest rooted cuttings (Figure 1). This could be that the presence of higher rooting hormone enhances the plant growth process henceforth root formation. During the study, same observations were made on: Average number of roots and rooting length (Figure 2). Saffari et al [9], noted that different concentrations of hormone had significant effect on number of roots, percentage survival of stem cutting. 


\subsection{Effect of different stem cuttings on the rooting success}

Softwood cuttings gave higher rooted cuttings than the other types of cuttings (Figure 1) Agbo and Obi [13] reported significant variability on rooting in refusus cuttings with higher percentage of rooted cuttings in softwood followed by Semi hardwood and Hardwood stem cuttings. During the same study, similar observations were made on: Number of rooted cuttings and Number of roots per cutting. (Figure 2). This could be also due to that fact that there is always a high presence of plant growth hormones in growing parts of the plant.

\subsection{Effect of the rooting medium type on root formation in stem cuttings of Carissa edulis}

Results in the study showed that sand was the best rooting media for the propagation of Carissa edulis stem cuttings, with (25) rooted cuttings (Figure 1). High rooting percentages have been obtained from Cordia alliodora stem cuttings propagated in sand media [12]. Sand was also identified as the best rooting media for Gongronema latifilia stem cuttings [14]. Mujuni et al [15] pointed out that sand is good rooting medium that provides good drainage, maintains a more or less uniform bed temperature, enables rooted plant parts to be dug up easily, it is not expensive, often readily available locally and can be reused.

\section{Conclusion}

Mass multiplication of Carissa edulis for on farm domestication and conservation can be achieved by propagation of softwood stem cuttings treated with $0.8 \mathrm{w} / \mathrm{w}$ IBA rooting hormone and placed in sterilized sand as a rooting media in a non-mist propagator.

\section{Compliance with ethical standards}

\section{Acknowledgments}

The authors would like thank NARO and NaFORRI Management and staff for their technical, financial and moral support.

\section{Disclosure of conflict of interest}

All authors declare that they do not have any conflict of interest.

\section{References}

[1] World Health Organization. (2004). WHO Guidelines on Good Agricultural and Collection Practices (CACP) for Medicinal Plants. Geneva, Switzerland.

[2] Pagliarulo CL, Hayden AL and Giacomelli GA. (2004). Potential for greenhouse aeroponic cultivation of Urtica dioica L. Acta Hort, 659.

[3] RKS Tiwari and Kuntal Das. (2010). Effect of stem cuttings and hormonal pre-treatment on propagation of Embelia tsjeriam and Caesalpinia bonduc, two important medicinal plant species. Journal of Medicinal Plants Research, 4(15), 1577-1583.

[4] Ammarellou Ali, Kazemeitabar Kamal, Najafei Hamid Zarreinei, Mortazavei, Najmaddin and Nasimeh. (2012). Effects of different culture media on rooting of Urtica dioica L. stem cuttings. Journal of Soil Science and Environmental Management, 3(7), 172-175.

[5] Hanan M. Al-Youssef and Wafaa HB Hassan. (2017). Chemical constituents of Carissa edulis Vahl. Arabian Journal of Chemistry. King Saud University

[6] Thompson Mutshinyalo and Refilwe Malatji. (2012). Carissa edulis. Walter Sisulu National Botanical Garden.

[7] Orwa C, Mutua A, Kindt R, Jamnadass R and Simons A. (2009). Agroforestree Database: a tree reference and selection guide version 4.0 .

[8] Nampewo N. (2013). Saving Mabira Rainforest: Using Public Interest Litigation in Uganda to Save Mabira and Other Rainforests. Boston College. Environmental Affairs Law Review, 40(2), 523-553.

[9] M Saffari and VR Saffari. (2012). Effects of media and indole butyric acid (IBA) concentrations on hop bush (Dodoneae viscosa L.) cuttings in green house. ANNALS OF FOREST RESEARCH. Ann. For. Res, 55(1): 61-68. 
[10] Anand Singh Bisht and Ajay Ballabh Bhatt. 2014. Effect of hormonal and soil treatment on the growth performance of valuable medicinal plant Acorus calamus Linn. World journal of pharmacy and pharmaceutical sciences, 3(5), 1156-1168.

[11] Hopkins WG. (1999). Introduction to Plant Physiology. John Wiley and Sons.

[12] Leakey RRB, Mesen JF, Tchoundjeu Z, Longman KA, Dick JMCP, Newton A, Martin A, Grace J, Munro RC and Muthoka PN. (1990). Low technology techniques for the vegetative propagation of tropical trees. Commonwealth. For. Rev, 69(3): 247-257.

[13] Agbo CU and Omaliko CM. (2006). Initiation and growth of shoots of Gongronema latifolia Benth stem cuttings in different rooting media. Afr. J. Biotechnol, 5(5): 425-428.

[14] Agbo CU and Obi IU. (2007). Variability in Propagation Potentials of Stem Cuttings of Different Physiological Ages of Benth. Department of Crop Science, University of Nigeria. Nsukka, Nigeria. World Journal of Agricultural Sciences, 3(5): 576-581.

[15] Denis BM, Fred K and Mariam MG. (2015). Bamboo handbook. Lambert Academic Publishing. 